\title{
O TWITTER COMO FONTE PARA O JORNALISMO
}

\author{
TWITTER AS A SOURCE FOR JOURNALISM
}

\section{EL TWITTER COMO FUENTE PARA EL PERIODISMO}

\author{
Gabriela da Silva Zago \\ Doutoranda e Mestre em Comunicação e Informação pela \\ Universidade Federal do Rio Grande do Sul \\ gabrielaz@gmail.com
}

\begin{abstract}
Resumo
O trabalho tem por objetivo discutir o papel do microblog Twitter enquanto fonte para o jornalismo. Parte-se de uma breve reflexão sobre as fontes utilizadas no jornalismo, seguida de considerações específicas sobre a utilização de frases ditas por famosos e por pessoas comuns no Twitter como fonte para a produção de notícias. Utiliza-se como ponto de partida para a reflexão, em caráter ilustrativo, notícias publicadas em Zero Hora.com e Folha.com que fazem menção a frases ou acontecimentos relacionados ao Twitter. O que se observa é um predomínio de fontes tradicionais, ainda que suas declarações possam ser obtidas por um meio não convencional.
\end{abstract}

Palavras-chave: jornalismo; fontes; Twitter.

\section{Resumen}

El artículo se propone a discutir el papel del microblog Twitter como fuente para el periodismo. Se inicia con una breve reflexión a cerca de las fuentes utilizadas en el periodismo, seguido por consideraciones específicas sobre el uso de frases pronunciadas por gente famosa y ordinaria en Twitter como fuente para la producción de noticias. Se utiliza como punto de partida para la reflexión, como ilustración, notícias publicadas en Zero Hora.com y Folha.com que mencionan frases o acontecimientos relacionados con Twitter. Lo que vemos es un predominio de fuentes tradicionales, aunque suas declaraciones pueden ser obtenidas por un medio no convencional.

Palabras-clave: periodismo; fuentes; Twitter.

\begin{abstract}
This paper aims to discuss the role of the microblog Twitter as a source for journalism. It starts with a brief reflection on the sources used in journalism, followed by specific considerations on the use of quotes from Twitter by famous and ordinary people as a source for news production. We use as a starting point for the discussion, illustratively, news published on Zero Hora.com and Folha.com that mention quotes or events related to Twitter. What we see is a predominance of traditional sources, even though the statements can be obtained by an unconventional mean.
\end{abstract}

Keywords: journalism; sources; Twitter.

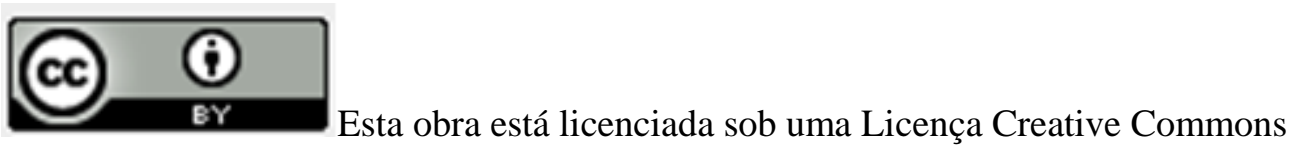




\section{INTRODUÇÃO}

Ainda que um limite de 140 caracteres possa ser considerado, por si só, um tanto reducionista, o Twitter tem sido apropriado para as mais diversas e criativas finalidades. De plataforma virtual para protestos contra o senador José Sarney ${ }^{1}$, a espaço onde se buscam informações sobre um incêndio no Rio de Janeiro ${ }^{2}$, passando por via para pressionar o Estado a fornecer medicamentos ${ }^{3}$ e até mesmo espaço ao qual famosos e anônimos recorrem quando falta energia, como no caso do "apagão" que atingiu parte do país em novembro de $2009^{4}$. O que há em comum entre esses e outros assuntos que começaram a ser discutidos no Twitter é o fato de que posteriormente vieram a receber atenção dos jornais de referência, na forma de notícias variadas sobre o tema.

Com o crescimento e a popularização das redes sociais na Internet, elas passam cada vez mais a ser objeto de matérias em jornais de referência. Ainda que muitas vezes a própria rede esteja em pauta, há vezes em que o conteúdo que circula nesses espaços se torna fonte para notícias.

Com base nesse cenário, o presente trabalho tem por objetivo traçar considerações sobre as fontes utilizadas no jornalismo a partir da identificação e análise de situações em que o Twitter serviu como fonte de notícias. As considerações são traçadas a partir do mapeamento de menções ao Twitter na primeira página dos jornais online Zero Hora.com e Folha.com num período de seis meses, de novembro de 2009 a abril de 2010. Identificou-se um total de 91 notícias na primeira página dos jornais com a palavra Twitter, sendo 30 em Zero Hora.com e 61 na Folha.com.

$\mathrm{O}$ artigo está dividido da seguinte forma: em um primeiro momento, discute-se as noção de fonte no jornalismo; a seguir, faz-se uma breve discussão sobre o uso das redes sociais como fonte para o jornalismo; o passo seguinte envolve a discussão acerca da utilização do Twitter como fonte para o jornalismo.

\footnotetext{
1 “Movimento 'Fora Sarney' prepara manifestações no país", Folha.com, 14 ago. 2009. Disponível em <http://www1.folha.uol.com.br/folha/brasil/ult96u609688.shtml>. Acesso em 03 jul. 2010.

2 "Incêndio atinge o Morro dos Cabritos no Rio de Janeiro", Terra, 20 jun. 2010. Disponível em $<$ http://noticias.terra.com.br/brasil/noticias/0,,OI4508323-EI8139,00-Incendio+atinge+o+Morro+dos+Cabritos+ no+Rio+de+Janeiro.html>. Acesso em 03 jul. 2010.

3 "José Serra garante pelo Twitter medicamento a jornalista com doença rara", Portal Imprensa, 17 mar. 2010. Disponível em <http://portalimprensa.uol.com.br/portal/ultimas_noticias/2010/03/17/imprensa34440.shtml>. Acesso em 03 jul. 2010.

4 ““Quem apagou a luz?', pergunta Luciano Huck no Twitter durante apagão”, G1, 11 nov. 2009. Disponível em <http://g1.globo.com/Sites/Especiais/Noticias/0,,MUL1374531-17814,00-QUEM+APAGOU+A+LUZ+

PERGUNTA+LUCIANO+HUCK+NO+TWITTER+DURANTE+APAGAO.html>. Acesso em 03 jul. 2010.
} 


\section{AS FONTES NO CONTEXTO DA APURAÇÃO JORNALÍSTICA}

O processo jornalístico envolve diversas etapas, que vão desde a apuração até a circulação, passando pela produção da notícia e por seu posterior consumo pelo público (MACHADO \& PALACIOS, 2007). A apuração, comumente apontada como a primeira das etapas jornalísticas, compreende diversas atividades, da definição da pauta até a verificação de dados para a produção de uma notícia (VIRISSIMO, 2009). As informações podem ser recolhidas através de variadas técnicas jornalísticas, como a escolha das fontes de informação, ou a realização de entrevistas. Pode-se, ainda, recorrer à Internet como fonte para a produção de notícias (MACHADO, 2002), ou se valer do poder da inteligência coletiva e contar com diversos e variados colaboradores numa apuração distribuída (TRÄSEL, 2009). Assim, a apuração compreende as tarefas de se reunir materiais e informações sobre um determinado acontecimento, a partir de variadas formas, para que se torne viável, posteriormente, transformá-lo em notícia.

A notícia, um dos principais produtos jornalísticos, é o resultado de uma construção social em torno de dois agentes: "O primeiro é a fonte de informação, com interesses na promoção e divulgação de certos factos. O segundo interveniente é o jornalista, que noticia os acontecimentos e desoculta segredos das fontes" (SANTOS, 2004, p. 1). O autor faz a ressalva de que o cenário é um tanto mais complexo, na medida em que jornalista e fontes possuem interesses próprios, muitas vezes conflitantes, e esse tensionamento irá se refletir no produto jornalístico.

As fontes correspondem aos promotores das notícias (ALSINA, 2009). Nesse contexto, "os jornalistas obtêm as notícias de fontes que eles observam ou entrevistam" (GANS, 2005, p. 116) ${ }^{5}$. Assim, pode-se dizer que as fontes "são pessoas, são grupos, são instituições sociais ou são vestígios - falas, documentos, dados - por aqueles preparados, construídos, deixados" (PINTO, 2000, p. 278), enfim, tudo aquilo que compõe a matériaprima que irá constituir o produto jornalístico.

Há diversas classificações possíveis para as fontes, conforme o parâmetro adotado como referência (WOLF, 1999). Assim, elas podem ter caráter oficial ou não oficial, podem ser indivíduos ou representar instituições, podem ser pessoais ou documentais, entre outras classificações possíveis. Há ainda a diferenciação entre as fontes utilizadas e as fontes

\footnotetext{
${ }^{5}$ Tradução de: "Journalists obtain news from sources they observe or interview" (GANS, 2005, p. 116).
} 
mencionadas: embora diversas fontes possam ser usadas para a elaboração de uma notícia, nem todas elas serão efetivamente mencionadas no material (ALSINA, 2009).

Um aspecto importante relacionado às fontes diz respeito ao relacionamento entre jornalistas e fontes, em que pode acontecer uma completa interdependência entre ambos, a fonte e o jornalista podem cooperar, e há casos em que a fonte é praticamente quem faz a notícia (ALSINA, 2009). Em qualquer dos casos, o jornalista sabe - ou, pelo menos, deveria saber -, "que as fontes de informação não são desinteressadas" (TRAQUINA, 1996, p. 172), ou seja, ao fornecerem informações para jornalistas, as fontes buscam promover determinados interesses de caráter institucional ou pessoal, "quer dizer, estão implicadas e desenvolvem a sua actividade a partir de estratégias e com tácticas bem determinadas" (PINTO, 2000, p. 278). Pelo fato de as fontes serem interessadas, a relação entre jornalistas e fontes pode ser vista como um campo de negociação de interesses (GOMIS, 2004). Nesse contexto, para Gomis (2004), o sistema político é o principal fornecedor de fatos à imprensa, devido ao interesse existente em se dar visibilidade aos atos politicos.

Há cooperação e disputa entre jornalistas e fontes. Assim, "O que lemos na notícia resulta de um complexo processo, em que nem todas as interacções dos agentes sociais aparecem visíveis nos textos jornalísticos” (SANTOS, 2004, p. 8).

Nesse sentido, para Gans (2005, p. 116), “o relacionamento entre jornalistas e fontes lembraria uma dança, na medida em que as fontes buscam acesso aos jornalistas, e os jornalistas buscam acesso às fontes" ${ }^{\prime 6}$, com tendência para que a dança seja conduzida por um dos parceiros - ainda que na maior parte das vezes a dança seja liderada pelas fontes.

Nem mesmo o acesso das fontes aos jornalistas é igualitário; varia conforme o poder da fonte: "O presidente dos Estados Unidos tem acesso instantâneo a todos os meios noticiosos a qualquer momento que quiser; os menos poderosos precisam recorrer a distúrbios civis para obtê-lo" (GANS, 2005, p. 119) ${ }^{7}$.

Para Gans (2005), os repórteres enfrentam o dilema de dispor de uma pequena quantidade de tempo para reunir a maior quantidade possível de informações sobre os fatos. Nesse contexto, recorrer às redes sociais na Internet tem emergido como uma alternativa para a busca de fontes rápidas e acessíveis para notícias.

\footnotetext{
${ }^{6}$ Tradução de: "The relationship between sources and journalists resembles a dance, for sources seek access to journalists, and journalists seek access to sources" (GANS, 2005, p. 116).

${ }^{7}$ Tradução de: "The president of the United States has instantaneous access to all news media whenever he wants it; the powerless must resort to civil disturbances to obtain it” (GANS, 2005, p. 119).
} 


\section{REDES SOCIAIS COMO FONTE PARA O JORNALISMO}

O conteúdo que circula nas redes sociais na Internet, como no Twitter, pode, coletivamente, servir de fonte para o jornalismo. Recuero (2009) sistematiza três relações possíveis entre jornalismo e redes sociais: as redes sociais podem atuar como fontes produtoras de informação, como filtros de informação, ou ainda como espaços de reverberação dessas informações. Assim, para a autora, a rede social será ponto de partida para uma notícia quando uma discussão surgida na rede acaba recebendo atenção da mídia. Isso ocorre, por exemplo, quando acontecimentos que tomam lugar em sites de redes sociais servem como pauta para os veículos jornalísticos, ainda que não haja intencionalidade por parte dos envolvidos em virar notícia. Nesse sentido, "as redes sociais, enquanto circuladoras de informações, são capazes de gerar mobilizações e conversações que podem ser de interesse jornalístico na medida em que essas discussões refletem anseios dos próprios grupos sociais" (RECUERO, 2009, p. 47).

Para Machado (2002), a estrutura descentralizada do ciberespaço passou a permitir que, ao menos em tese, qualquer um se transforme em uma fonte potencial para o jornalismo. A Internet diversifica as fontes - o próprio usuário passa a poder ser fonte, recorre-se não apenas a fontes oficiais. Isso também aumenta a responsabilidade dos usuários como fontes para jornalistas. Cresce, ainda, a importância de se buscar critérios próprios para avaliar a credibilidade das fontes. Para Marinho (2000), um elemento fundamental na relação entre jornalistas e fontes é a confiança - um jornalista tenderá a recorrer mais vezes a fontes com as quais mantém um histórico de confiança.

O próprio Twitter pode por vezes servir como fonte de notícias, como quando frases ditas por políticos ou celebridades na ferramenta servem de pauta para a produção de notícias em um determinado veículo. Ao analisarem um caso específico de uso do Twitter como fonte pelo jornalismo ${ }^{8}$, Vieira \& Cervi (2010, p. 12) concluem que "As redes sociais não foram usadas para gerar uma cobertura jornalística diferente da convencional nesse caso”. Apesar do potencial de utilizar o Twitter para dar voz a uma multiplicidade de vozes, o que os autores

\footnotetext{
${ }^{8} \mathrm{O}$ caso por eles estudado foi como as postagens feitas no Twitter em fevereiro de 2010 pelo então governador do estado do Paraná, Roberto Requião, acerca de uma rixa sua com o então Ministro do Planejamento, Paulo Bernardo, foram pautadas na imprensa paranaense. Os autores observaram que, apesar de o Twitter ter pautado os veículos, não se procurou promover uma diversidade de vozes; apenas as fontes oficias envolvidas foram citadas.
} 
observaram "Foi a reprodução das práticas e rotinas de produção da notícia, porém, agora, sem a necessidade de fazer perguntas antes de obter as respostas" (VIEIRA \& CERVI, 2010, p. 12). A mera utilização do Twitter como fonte não assegura que o produto resultante seja diferente do que se obteria a partir da utilização de fontes tradicionais de notícias. Já o trabalho de Lopes (2010), por sua vez, procurou identificar as menções ao Twitter no período de uma semana na versão impressa do jornal Folha de S.Paulo. A autora identificou 30 menções em 13 matérias no período, tendo classificado seis como tendo o Twitter como assunto principal, quatro como tweets que viraram notícia e três como declarações de fontes via Twitter.

\section{O TWITTER COMO FONTE}

Para discutir a utilização do Twitter como fonte para o jornalismo, utilizou-se como ponto de partida a identificação e análise de situações em que o Twitter serviu como fonte em matérias publicadas nos sites Zero Hora.com e Folha.com. Em um primeiro momento, são descritos os procedimentos metodológicos empregados. Logo após, os resultados são apresentados e discutidos.

A busca por notícias que utilizassem o Twitter como fonte se deu num período de seis meses, de novembro de 2009 a abril de 2010, a partir de três acessos diários aos sites Zero Hora.com e Folha.com, em horários variados, com um intervalo mínimo de quatro horas entre um acesso e outro, de modo a captar diferentes conteúdos na página inicial dos sites.

Optou-se por restringir a análise às matérias que figurassem na primeira página desses jornais online devido ao destaque conferido a tais notícias. "Na verdade, é a primeira página que atrai ou não o leitor. Sua decisão de ler depende do grau de atratividade da capa" (MOREIRA, 2004, p. 31). Devido a limitações de espaço, nem todos os assuntos podem figurar na primeira página. "Logo, só serão notícias de primeira página os fatos que se encaixarem nos critérios de noticiabilidade e que forem considerados mais importantes pelos editores" (CERVI \& HEDLER, 2010, p. 15), tendo em vista o objetivo de atrair leitores e vendas. Além disso, por se tratar da primeira página de um jornal online, passível de ser constantemente renovada, buscou-se distribuir os acessos ao longo do dia, de modo a captar possíveis variações nas manchetes em destaque na página inicial dos sites. Conforme 
colocado pela redação do UOL sobre a atualização de sua primeira página 9 , "A primeira página deve apresentar novidades para aqueles que a visitam várias vezes por dia, mas não pode, para isso, abdicar da responsabilidade de manter registradas por um período mais longo as notícias mais importantes e de maior impacto". Assim, embora a primeira página possa sofrer modificações a qualquer momento do dia, certos assuntos permanecem em destaque por mais tempo, conforme a importância conferida ao acontecimento.

A cada acesso, fez-se uma busca simples pela palavra "Twitter", a fim de se localizar a presença do termo em matérias referidas na primeira página do site. No total foram identificadas 30 menções ao Twitter na primeira página de Zero Hora.com e 61 na primeira página de Folha.com no período analisado. A partir da chamada com a palavra Twitter identificada na primeira página, procurou-se observar o conteúdo da notícia vinculada.

Das 91 notícias analisadas, identificou-se que 52 (57,1\%) traziam o Twitter como fonte. O Twitter foi classificado como fonte da notícia quando a notícia em si trazia citação a falas ditas na ferramenta, ou a acontecimentos que tiveram lugar no Twitter. Das notícias observadas, 44 traziam uma citação a algo dito no Twitter $(48,4 \%)$, ao passo que 47 não traziam citação de tweets $(51,6 \%)$. Em 42 das notícias nenhuma outra fonte, além de algo dito ou ocorrido no próprio Twitter, era mencionada no texto $(46,2 \%)$.

As notícias identificadas tratavam de temáticas variadas. As mais freqüentes foram famosos (com 17 ocorrências, 18,7\%), política (13 ocorrências, 14,3\%), Big Brother (11 ocorrências, $12,1 \%$ ), o próprio Twitter enquanto ferramenta (11 ocorrências, 12,1\%) e trânsito (9 ocorrências, 9,9\%). Entretanto, enquanto famosos, política e o próprio Twitter foram notícia em ambos os veículos, a temática trânsito apareceu junto à palavra Twitter apenas na primeira página da Zero Hora.com, ao passo que a temática Big Brother apareceu combinada a Twitter apenas na primeira página da Folha.com. Outros temas menos frequentes mas que também foram observados foram frases da semana (5 ocorrências, apenas na Folha.com, 5,5\%), promoções (4 ocorrências, 4,4\%), literatura (3 ocorrências, 3,3\%), negócios e ciência ( 2 ocorrências cada, 2,2\%). As demais temáticas, como clima, animais ou tecnologia, dentre outras, ocorreram apenas uma vez associadas ao Twitter na primeira página dos jornais analisados.

\footnotetext{
${ }^{9}$ Disponível em <http://noticias.uol.com.br/ultnot/2006/09/06/ult23u257.jhtm>. O UOL arquiva a imagem de sua primeira página quatro vezes por dia, o que pode ser utilizado para pesquisas futuras sobre o tema. $\mathrm{O}$ arquivo pode ser acessado em 〈http://noticias.uol.com.br/arquivohome/datas.jhtm〉.
} 
Um exemplo do uso de citação de tweets para a produção de uma matéria com a temática Big Brother pode ser visto na notícia de 15 de março de 2010 na Folha.com, em cuja chamada de capa lia-se "Ivete Sangalo faz campanha por Maroca no Twitter""10 (Figura 1).
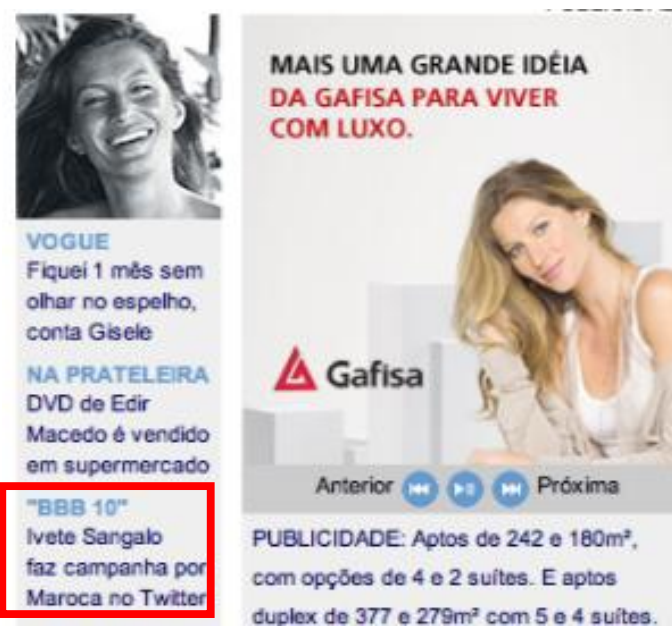

\section{Criminoso descreve como matou Glauco e seu filho; veja}

No Paraná, Carlos Sundfeld Nunes, apontado como assassino de Glauco e seu filho Raoni, está preso desde ontem. Ele confessou o crime à PF e em gravaçăo de TV.

- Criminoso atirou contra amigo de filho de Glauco

- Polícia ouve depoimentos sobre assassinato

- Criminoso está em cela isolada no Paraná

- Clinha de tempo mostra carreira de Glauco

ECONOMIA E CONSUMO

Banco do Brasil amplia oferta de crédito para pessoas fisicas em R\$ 8,2 bilhões

A medida deve beneficiar 1,4 milhăo de clientes, segundo o banco; essa é a $3^{a}$ ampliaçăo de crédito em um ano.

- Ministro prevê 200 mil empregos novos em fevereiro

- Retaliaçăo aos EUA baratear medicamentos e filmes ต..- .

Figura 1. Primeira página da Folha.com em 15 de março de 2010.

Fonte: http://www.folha.com.br

A notícia em si trazia citação a tweets, conforme se pode ver no Quadro 1. Muitas vezes a grafia desses tweets era adaptada para que pudesse ser transformada em uma citação entre aspas. Em outras situações, mais de um tweet era combinado para compor uma única citação na notícia. No Quadro 2 é possível ler os tweets das artistas que deram origem aos respectivos trechos da notícia na Folha.com.

Quadro 1. Trechos da notícia "Ivete Sangalo faz campanha por Maroca no Twitter".

\begin{tabular}{|l|l|}
\hline Fonte & Trecho da notícia na Folha.com \\
\hline $\begin{array}{l}\text { Ivete } \\
\text { Sangalo }\end{array}$ & $\begin{array}{l}\text { "O que? Maroca, conterrânea, no paredão? Ah, não vamos deixar isso } \\
\text { acontecer né. Juazeiro na cabeça!", escreveu Ivete, fazendo referência a } \\
\text { cidade em que as duas nasceram, na Bahia. }\end{array}$ \\
\hline Preta Gil & $\begin{array}{l}\text { "Vamos nos unir para Maroca ficar. A cara da união. Esse paredão } \\
\text { promete. Torço pra Maroca ficar. Ela fala muito, mas é autêntica, } \\
\text { divertida, e arretada. A Maroca é das minhas", escreveu. }\end{array}$ \\
\hline $\begin{array}{l}\text { Fernanda } \\
\text { Paes Leme }\end{array}$ & $\begin{array}{l}\text { "Vem fazer a Tessália aqui fora Michel", brincou, fazendo referência ao } \\
\text { que é dito pelo apresentador Pedro Bial quando os participantes são } \\
\text { eliminados. }\end{array}$ \\
\hline $\begin{array}{l}\text { Monique } \\
\text { Evans }\end{array}$ & $\begin{array}{l}\text { "Michel, você é falso! Maroca minha diversão!", escreveu a } \\
\text { apresentadora Monique Evans. "Nunca gostei dele!", completou. }\end{array}$ \\
\hline
\end{tabular}

Quadro 2. Tweets originais que compuseram a notícia na Folha.com.

\footnotetext{
${ }^{10}$ http://www1.folha.uol.com.br/folha/ilustrada/ult90u707099.shtml
} 


\begin{tabular}{|l|l|}
\hline Fonte & Tweets \\
\hline ivetesangalo & $\begin{array}{l}\text { Oq? Maroca, conterrânea no paredão? Ah, Não vamos deixar isso } \\
\text { acontecer ne hihihi. Juazeiro na cabeça!!!! }\end{array}$ \\
\hline pretamaria & $\begin{array}{l}\text { Tweet 1 - @ AnaMLamm vai pro paredão????? adoro, gosto dele, } \\
\text { depois do show então mais ainda mas a Maroca é das minhas, } \\
\text { beijos no David } \\
\text { Tweet2 - opiniões divididas, esse paredão promete, torço pra } \\
\text { Maroca ficar, ela fala muito mas é autentica, divertida, e arretada. } \\
\text { Tweet 3 - @ HugoGloss @ fepaesleme vamos nos unir pra Maroca } \\
\text { ficar a cara da união!!!!! }\end{array}$ \\
\hline fepaesleme & "Vem fazer a Tessália aqui fora Michel!!!" \\
\hline moniquevansreal & $\begin{array}{l}\text { Tweet 1 - Acho q o pessoal da Tess ta toda ajudando o Michel ..e } \\
\text { me atacando!!!Nunca gostei dele!!Esse sotaque!!E agora se } \\
\text { sentindo o lindao..please } \\
\text { Tweet 2 - Michel..vc e falsoooo!! Maroca minha diversão!!!! }\end{array}$ \\
\hline
\end{tabular}

Mas não são só os famosos que têm seus tweets reproduzidos nas páginas de um jornal online. Pode haver situações em que a fala de um cidadão comum na ferramenta Twitter pode ser transformada em fonte para uma notícia. No período observado, isso aconteceu na notícia de Zero Hora.com cuja chamada de capa era "Internautas relatam no Twitter desconforto com o calor" ${ }^{\prime 1}$, de 03 de fevereiro de 2010 (Figura 2).

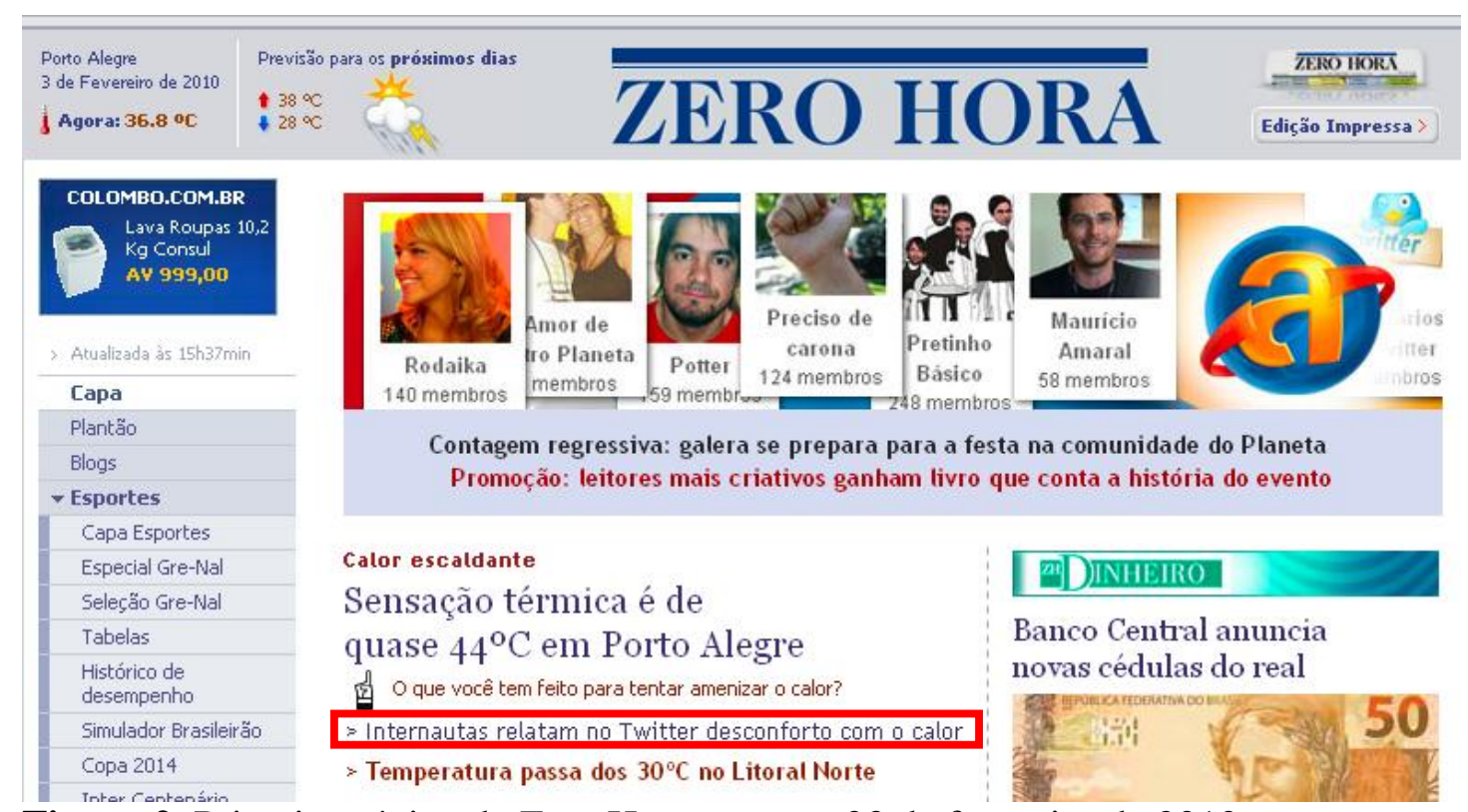

Figura 2. Primeira página de Zero Hora.com em 03 de fevereiro de 2010.

Fonte: http://zerohora.clicrbs.com.br

\footnotetext{
${ }^{11} \mathrm{http} / / /$ zerohora.clicrbs.com.br/zerohora/jsp/default.jsp?uf=1\&local=1\&section=Geral\&newsID=a2798110.xml
} 
$\mathrm{Na}$ ocasião, Porto Alegre registrou a temperatura mais quente do ano, chegando à sensação térmica de quase $44^{\circ} \mathrm{C}$. Os moradores da cidade utilizaram o Twitter para reclamar do calor. Essa notícia reproduzia o conteúdo dos tweets de sete usuários diferentes, dentre eles a mensagem de henriquevf: "Falta mto pro verão acabar? Forno Alegre não dá mais". Um fator interessante é que o jornal não procurou adaptar a linguagem das mensagens. Elas foram reproduzidas tal qual apareciam no Twitter.

A partir da observação da primeira página dos jornais online Zero Hora.com e Folha.com entre os meses de novembro de 2009 e abril de 2010, foi possível perceber alguns dos assuntos ocorridos no Twitter que foram transformados em notícia pelos jornais online, tornando visível a relação de complementaridade entre essas diferentes mídias.

Muitas das matérias referenciando o Twitter que recebiam destaque na primeira página desses jornais tratavam de temas relativos a celebridades ou a políticos - em especial no começo de 2010, em virtude da aproximação da época das eleições. Esses assuntos de certa forma costumam ser notícia regularmente - e nesse caso independe do fato de ter sido originado no Twitter para ser veiculado na primeira página do jornal. Assim, não chega a ser surpreendente que a declaração de uma pessoa famosa no Twitter acabe sendo apropriada por um jornal de referência e sirva de base para a produção de uma matéria. Do mesmo modo, as declarações feitas por políticos também gozam desse status. Nesses casos, essas declarações poderiam ter sido dadas em qualquer outro contexto, que não o Twitter, e mesmo assim se tornariam notícias. O diferencial diz respeito ao fato de que os jornalistas têm à sua disposição, 24 horas por dia, um conjunto de declarações por escrito, feitas espontaneamente ou não, por famosos ou políticos (ou por seus assessores), a partir das quais podem produzir suas matérias. Dumenco (2010) chega ao extremo de declarar a "morte do release", considerando a possibilidade de os famosos e as empresas poderem dar declarações, diretamente, através do Twitter, sem precisar convocar coletivas de imprensa, ou até mesmo sem precisar se preocupar com a correção ortográfica ou gramatical dos pequenos textos de até 140 caracteres cada.

Assim, a mera utilização do Twitter como fonte não assegura que o produto resultante seja diferente do que se obteria a partir da utilização de fontes tradicionais de notícias. Sabendo que possuem seus perfis no Twitter vigiados, daria para se questionar se os famosos não escolheriam cuidadosamente suas falas na ferramenta, já pensando na possibilidade de vir a se tornar fonte de notícias. Afinal, as fontes não são desinteressadas (TRAQUINA, 1996) e 
buscam promover seus interesses (GOMIS, 2004). Mesmo assim, também foram observados casos em que o indivíduo posteriormente parece ter se arrependido do que disse na ferramenta, como em uma notícia que traz tweets que o assessor e a namorada de Kaka teriam feito no Twitter ${ }^{12}$. A notícia informa que esses tweets foram posteriormente apagados. Mas ficaram no ar tempo suficiente para serem flagrados pela redação e transformados em notícia.

Através da observação das notícias também foi possível perceber que grandes acontecimentos, que atingem um grande quantidade de pessoas, também se tornam notícia com referência ao Twitter. Por exemplo, em caso de terremotos ou de manifestações em que o Twitter desempenhou papel relevante, como no caso do apagão ou do terremoto em São Paulo, ambos ocorridos em 2009. São raros os casos em que tweets feitos por pessoas comuns ganham a mídia, como aconteceu na notícia sobre a temperatura em Porto Alegre, em Zero Hora.com. Nesse caso, pode-se dizer que os indivíduos se tornaram "fontes acidentais", na medida em que suas declarações espontâneas na ferramenta não foram feitas objetivando figurar em uma notícia em um jornal online. Mas mesmo cidadãos comuns podem se utilizar do Twitter com a finalidade de buscar receber posterior atenção da mídia, como quando atuam como testemunhas oculares de fatos. Isso pode acontecer, por exemplo, quando uma manifestação específica iniciada no Twitter recebe atenção de jornais de referência, como no caso das eleições do Irã, em que os protestos realizados no Twitter acabaram despertando a atenção dos jornais, que posteriormente produziram textos jornalísticos variados sobre o assunto.

Há ainda inúmeras vezes em que uma pauta sugerida ou surgida via Twitter se torna notícia nos jornais online, porém sem mencionar em nenhum momento que ela teria surgido no Twitter. Esse tipo de relação ocorre também a partir de outros meios, como quando alguém manda e-mail ou liga para a redação informando sobre um determinado acontecimento. Nesses casos, a mera observação do produto - a notícia - é incapaz de revelar se a matéria teve sua origem a partir de algo que foi dito no Twitter, ou sugerido através da ferramenta.

Mesmo quando uma informação que circula no Twitter adquire proporções tais que vira notícia em jornais online de referência, pode ser que o próprio Twitter não seja mencionado como lugar de onde partiu aquela informação, como ocorreu no boato sobre a morte do cantor Dinho Ouro Preto, surgido em novembro de 2009 no Twitter (ZAGO, 2010). Na ocasião, o surgimento do boato no Twitter fez com que a assessoria de imprensa do cantor

\footnotetext{
12 “Mulher e assessor de Kaká usam Twitter para criticar técnico do Real”, Folha.com, 11 mar. 2010. Disponível em <http://www1.folha.uol.com.br/folha/esporte/ult92u705360.shtml>. Acesso em 06 jul. 2010.
} 
fizesse um release informando aos jornais que o cantor passava bem. $O$ release não mencionava a existência do boato no Twitter, embora tivesse sido motivado pelo boato. Com isso, os veículos se dividiram entre aqueles que mencionavam o boato, e aqueles que simplesmente noticiaram que o cantor passava bem, a partir do release distribuído pela assessoria de imprensa do cantor.

Desse modo, o trabalho do jornalista nesses veículos se aproxima ao papel de um jornalista sentado (PEREIRA, 2004), na medida em que o profissional não precisa sair da redação para produzir uma notícia. De fato, a mera observação do que é dito por políticos e famosos no Twitter pode bastar para que se obtenha um fluxo contínuo de frases e citações que possam ser transformadas em notícias.

Assim, ainda que a possibilidade de utilização do ciberespaço como fonte para o jornalismo tenha o potencial de vir a mobilizar uma maior diversidade de fontes, vindo a complementar outras fontes tradicionais dentro e fora do ciberespaço (MACHADO, 2002), o que se observa é um predomínio de fontes tradicionais, ainda que por meios não tradicionais de obtenção de tais declarações (como no caso de se recorrer ao perfil de um político no Twitter para buscar frases de efeito para ilustrar uma notícia). Uma possível explicação para o fato de predominar o uso do Twitter como fonte em caso de declarações de famosos e políticos diz respeito à credibilidade (MARINHO, 2000) - essas fontes já trazem um histórico de credibilidade advindo de outros meios. Assim, o jornalista tende a confiar que as informações disponibilizadas pelo ator no Twitter serão verdadeiras. Talvez por isso sejam bem mais raros os casos em que frases ditas por pessoas comuns no Twitter sirvam como fonte para o jornalismo.

Outro fator que pode ser percebido através da observação das primeiras páginas dos jornais online diz respeito ao encadeamento midiático (PRIMO, 2008) entre Twitter e jornais online. Além do fato de o Twitter poder servir como fonte de notícias para o jornalismo online, e do potencial de o caminho inverso também ocorrer (ou seja, de usuários lerem a notícia no jornal e retomarem a discussão sobre o tema no Twitter, a partir de links), pode-se dizer que Twitter e jornais online se complementam, na medida em que as notícias podem ser úteis como filtros da informação que circula no Twitter. $\mathrm{O}$ fato de tais informações serem apropriadas pela instituição jornalística as confere o status de notícia, de assunto de interesse público.

\section{CONSIDERAÇÕES FINAIS}


O trabalho procurou identificar as situações em que o Twitter aparece como fonte de notícias em jornais online de referência, a partir da observação da primeira página dos jornais Folha.com e Zero Hora.com num período de seis meses. Foram identificadas 91 chamadas de capa nesse período, e analisadas as notícias associadas a essas chamadas.

Percebeu-se que cerca de metade dessas notícias utilizavam o Twitter como fonte, ou seja, traziam a citação a um ou mais tweets. A outra metade partia de algo acontecido no Twitter ou com a ferramenta, utilizando o Twitter como pauta para a produção da notícia, recorrendo, muitas vezes, a outras fontes. $\mathrm{O}$ uso do Twitter como fonte predominou em notícias relacionadas a famosos e políticos, o que leva a crer que tais declarações seriam também transformadas em notícia, ainda que tivessem sido dadas em outros suportes ou contextos. O diferencial diz respeito ao fato de que os jornalistas dispõem de um meio para acompanhar o que dizem famosos e políticos o tempo todo, sem precisar sair da redação.

Twitter e jornais online se encadeiam, um meio vindo a complementar o outro. Mesmo notícias que sejam meras reproduções de algo dito no Twitter podem ser úteis para aqueles que não viram o conteúdo circular na ferramenta, por exemplo. Nessas ocasiões, os jornais online de referência atuariam como filtro das informações que circulam no Twitter.

Trabalhos futuros poderão ser desenvolvidos no sentido de identificar outras modificações que a introdução de redes sociais na Internet e de serviços como o Twitter podem provocar nas etapas do processo jornalístico, desde a apuração até o consumo de informações.

\section{Referências}

ALSINA, M.R. A construção da notícia. Petrópolis: Vozes, 2009.

CERVI, E. U.; HEDLER, A. P. Como os jornais brasileiros dão visibilidade a temas públicos: uma análise comparativa sobre os assuntos que ocupam as manchetes de periódicos diários de circulação local, regional e nacional. Revista FAMECOS, v.17, n.1, 2010.

DUMENCO, S. RIP, the Press Release (1906-2010) - and Long Live the Tweet. Advertising Age, 13 set. 2010. Disponível em <http://adage.com/mediaworks/article?article_id=145838>. Acesso em 16 set. 2010.

GANS, H.J. Deciding What's News: A study of CBS Evening News, NBC Nightly News, Newsweek, and Time. 2.ed. Evanston, Illinois: Northwestern University Press, 2005. 
GOMIS, L. Os interessados produzem e fornecem os fatos. Estudos em Jornalismo e Mídia, v. 1, n. 1, 2004.

LOPES, F. V. A reconfiguração dos veículos tradicionais de informação frente à popularização das mídias sociais. In: XV Congresso de Ciências da Comunicação na Região Sudeste, 2010, Vitória. Anais... Vitória, ES 2010.

MACHADO, E. O ciberespaço como fonte para os jornalistas. In: Biblioteca On-line de Ciências da Comunicação. Covilhã: Universidade de Beira Interior, 2002. Disponível em <http://www.bocc.ubi.pt/pag/_texto.php3?html2=machado-elias-ciberespacojornalistas.html>. Acesso em 06 jul. 2010.

MARINHO, S. O valor da confiança nas relações entre jornalistas e fontes de informação. In: MARTINS, M.L. (Org.) Comunicação e Sociedade 2. Braga: Centro de Ciências Históricas e Sociais da Universidade do Minho, 2000, p. 351-356.

MOREIRA, D. J. 11 de Setembro de 2001: Construção de uma catástrofe nas primeiras páginas de jornais impressos. Dissertação de Mestrado (Mestrado em Comunicação e Semiótica), PUC-SP, 2004.

PEREIRA, F. H. O 'Jornalista Sentado' e a Produção da Notícia on-line no CorreioWeb. Em Questão, v.10, n.1, 2004.

PINTO, M. Fontes jornalísticas: contributos para o mapeamento do campo. MARTINS, M.L. (Org.) Comunicação e Sociedade 2. Braga: Centro de Ciências Históricas e Sociais da Universidade do Minho, 2000, p. 277-294.

PRIMO, A. A cobertura e o debate público sobre os casos Madeleine e Isabella: encadeamento midiático de blogs, Twitter e mídia massiva. Galáxia (PUCSP), v. 16, p.43$59,2008$.

RECUERO, R. Redes sociais na Internet, difusão de informação e jornalismo: elementos para discussão. In: SOSTER, D.A.; SILVA, F.F. (Orgs.). Metamorfoses jornalísticas 2: a reconfiguração da forma. Santa Cruz do Sul: EDUNISC, 2009, p. 37-55.

SANTOS, R. A negociação entre fontes de informação e jornalistas em estudos de casos. In: XIX Congreso Internacional de Comunicación, Pamplona, Espanha. Anais... Pamplona, 2004.

TRAQUINA, N. As Notícias. In: TRAQUINA, N. Jornalismo: Questões, Teorias e "Estórias". Lisboa: Vega, 1996.

TRÄSEL, M. A apuração distribuída como técnica de webjornalismo participativo. In: VII SBPJor, São Paulo. Anais... São Paulo, SP, 2009.

VIEIRA, J. F.; CERVI, E. U. O Twitter como pauta no jornalismo politico do Paraná. In: XI Congresso de Ciências da Comunicação na Região Sul, Novo Hamburgo, 2010, Novo Hamburgo. Anais... Novo Hamburgo, 2010. 
VIRISSIMO, V.A. Apuração na Internet: Definição e Características. Um estudo de caso om jornalistas e rádio, televisão, jornal e internet do Grupo RBS de Florianópolis. Dissertação (Mestrado em Jornalismo), UFSC, 2009.

WOLF, M. Teorias da Comunicação. 5.ed. Lisboa: Editorial Presença, 1999.

ZAGO, G. S. Boatos que Viram Notícia: Considerações sobre a circulação de informações entre sites de redes sociais e mídia online de referência. In: XI Congresso de Ciências da Comunicação na Região Sul, 2010, Novo Humburgo. Anais... Novo Hamburgo, RS, 2010.

Original recebido em: 02/04/2011

Aceito para publicação em: 29/11/2011

Resumo dos autores:

Gabriela da Silva Zago possui graduação em Comunicação Social - Habilitação em Jornalismo pela Universidade Católica de Pelotas (2008), graduação em Direito pela Universidade Federal de Pelotas (2009) e mestrado em Comunicação e Informação pela Universidade Federal do Rio Grande do Sul (2011). Atualmente é doutoranda da Universidade Federal do Rio Grande do Sul e repórter - WAVE Magazine. Tem experiência na área de Comunicação, com ênfase em Cibercultura, atuando principalmente nos seguintes temas: twitter, redes sociais, jornalismo, microblogs e blogs.

http://buscatextual.cnpq.br/buscatextual/visualizacv.do?id=K4239019E0 